\title{
Optimum Design of Stator and Rotor Shape for Cogging Torque Reduction in Interior Permanent Magnet Synchronous Motors
}

\author{
Ju-Seong Yu ${ }^{*}$, Han-Wook Cho ${ }^{\dagger}$, Jang-Young Choi ${ }^{*}$, Seok-Myeong Jang ${ }^{*}$, and Sung-Ho Lee ${ }^{* *}$ \\ *Dept. of Electrical Engineering, Chungnam National University, Daejeon, Korea \\ ${ }^{\dagger}$ Dept. of Electric, Electronic \& Communication Eng. Edu., Chungnam National University, Daejeon, Korea \\ ${ }^{* *}$ Korea Institute of Industrial Technology (KITECH), Gwangju, Korea
}

\begin{abstract}
This paper deals with the optimum design of the stator and rotor shape of the interior permanent magnet synchronous motors (IPMSM) that are used in applications for automobiles. IPMSMs have the following advantages: high power, high torque, high efficiency, etc. However, cogging torque which causes noise and vibrations is generated at the same time. The optimum design of shape of a IPMSM was carried out with the aim of reducing cogging torque. Six variables which affect to the performance of a IPMSM are chosen. The main effect variables were determined and applied to the response surface methodology (RSM). When compared to the initial model using the finite elements method (FEM), the optimum model highly reduces the cogging torque and improves the total harmonics distortion (THD) of the back-electro motive force (EMF). A prototype of the designed model was manufactured and experimented on to verify the feasibility of the IPMSM.
\end{abstract}

Key words: Cogging torque, Fan motor, Interior permanent magnet synchronous motor, Optimum design, Response surface methodology

\section{INTRODUCTION}

Although gasoline engines have improved a lot, they are still not very efficient at turning chemical energy into mechanical power. Most of the energy in gasoline is converted into heat, and it is a job of the cooling system to take care of that heat. The primary job of the cooling system is to keep the engine from overheating by transferring this heat to the air. However, the cooling system has several other important jobs. Vehicle engines run best at a fairly high temperature. When an engine is cold, its components wear out faster, and the engine is less efficient and emits more pollution. Therefore, another important job of the cooling system is to allow the engine to heat up as quickly as possible, and then to keep the engine at a constant temperature. Therefore, the development of cooling fan motors is an active field of research because the cooling systems in vehicles play a very important role which extends

Manuscript received Jan. 29, 2013; revised Mar. 29, 2013

Recommended for publication by Associate Editor Jin Hur.

†Corresponding Author: hwcho@cnu.ac.kr

Tel: +82-421-8581, Fax: +82-822-4933, Chungnam National University

*Electrical Engineering, Chungnam National University, Korea

${ }^{* *}$ Korea Institute of Industrial Technology (KITECH), Korea

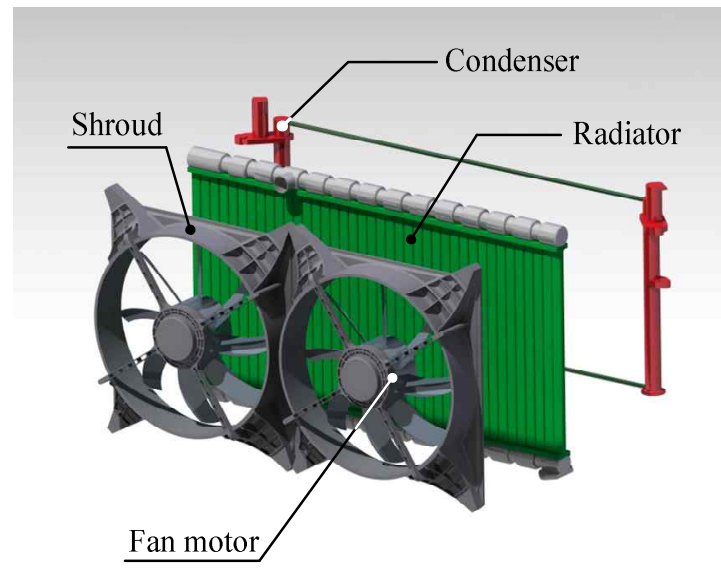

Fig. 1. Automotive cooling devices and fan motor.

the lifetime of the machine.

This paper presents an optimum design shape of the interior permanent magnet synchronous motor (IPMSM) for automobile cooling device applications. Fig. 1 shows an automotive cooling device and fan motor. For the cooling fan motor an IPMSM, among the many motor types, is supplied due to its high reliability, high efficiency, and power density. However, due to the configuration of the rotor the IPMSM 


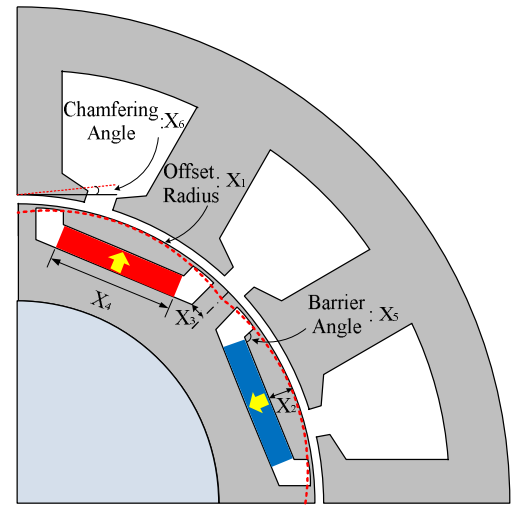

Fig. 2. Configuration and design variables for IPMSM.

TABLE I

SPeCificATIONS AND Design PARAMETERS OF INITIAL IPMSM MODEL

\begin{tabular}{c|c|c|c}
\hline Item & Value & Item & Value \\
\hline Input Voltage & $12 \mathrm{~V}$ & Speed & $1800 \mathrm{rpm}$ \\
\hline $\begin{array}{c}\text { Stator Outer/Inner } \\
\text { Diameter }\end{array}$ & $116 / 72 \mathrm{~mm}$ & $\begin{array}{c}\text { Rotor uter/Inner } \\
\text { Diameter }\end{array}$ & $71 / 48 \mathrm{~mm}$ \\
\hline Bridge Thickness & $0.5 \mathrm{~mm}$ & Airgap & $0.5 \mathrm{~mm}$ \\
\hline Rib & $4 \mathrm{~mm}$ & Remanence $\mathrm{B}_{\mathrm{r}}$ & $1.3 \mathrm{~T}$ \\
\hline Number of Slot & 12 & Number of Pole & 8 \\
\hline Core Material & $50 \mathrm{PN} 470$ & Magnet & $\mathrm{N} 42 \mathrm{SH}$ \\
\hline Winding & concentrated & Axial Length & $18 \mathrm{~mm}$ \\
\hline
\end{tabular}

produces a significant amount of cogging torque, and this will generate vibration and noise, which can be a major problem [1].

The aim of this study is to reduce cogging torque with an optimization method using a response surface methodology (RSM) based on a statistic approximate technique.

The initial IPMSM model is designed with 4 parallel branch concentrated windings and a delta connection due to the use of the existing low tension infrastructures. The variables influencing the performance in the configuration of the IPMSM were considered and the optimum shape design was carried out. This reduced the cogging torque and the THD without a significant decrease in performance for the IPMSM. In addition, the initial and optimum models are analyzed for the main characteristics and compared to the FEM. These results are verified by experiments.

\section{OPTIMUM DESIGN OF AN IPMSM USING THE RSM}

\section{A. Initial Model Design and Design Variables}

Fig. 2 shows the configuration of the IPMSM and its design variables. The IPMSM consists of a 12-slot stator with concentrated windings and 8-pole permanent magnets buried in the rotor. The permanent magnets are Nd-Fe-B (N42SH) magnets with a high heat-resisting property.

The detailed specifications of the initial IPMSM are shown

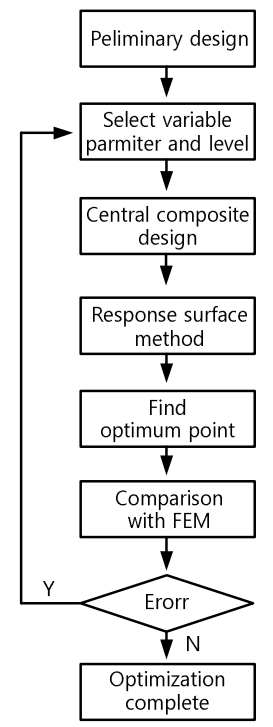

Fig. 3. Flow chart for optimum design.

TABLE II

DESIGN VARIABLES AND LEVEL

\begin{tabular}{c|c|c|c}
\hline $\begin{array}{c}\text { Design variables and } \\
\text { Level }\end{array}$ & -1 & 0 & 1 \\
\hline $\mathrm{X}_{1}(\mathrm{~mm})$ & 2 & 4 & 6 \\
\hline $\mathrm{X}_{2}(\mathrm{~mm})$ & 2 & 3 & 4 \\
\hline $\mathrm{X}_{3}(\mathrm{~mm})$ & 1 & 2 & 3 \\
\hline $\mathrm{X}_{4}(\mathrm{~mm})$ & 14.5 & 15 & 15.5 \\
\hline $\mathrm{X}_{5}($ Deg.) & 110 & 130 & 150 \\
\hline $\mathrm{X}_{6}$ (Deg.) & 0 & 2 & 4 \\
\hline
\end{tabular}

in Table I. Due to the large power consumption of EVs and HEVs, the system for a $42 \mathrm{~V}$ source is under development but the existing infra is $12 \mathrm{~V}$.

In this study, the initial IPMSM model was designed with a $12 \mathrm{~V}$ input voltage source for the vehicle engine cooling system. The bridge thickness is fixed at $0.5 \mathrm{~mm}$ to prevent leakage flux and in considerations of manufacturing difficulties.

The main design variables which have an influence on the optimization selected parameters, from $\mathrm{X} 1$ to $\mathrm{X} 6$, in figure 2 : "X1", radius of the offset rotor center; "X2", distance from the airgap; "X3", half thickness of the ribs; "X4", thickness of the permanent magnet; "X5", angle between the flux barrier and the permanent magnet; and "X6", chamfering angle of the stator teeth.

\section{B. Stator and Rotor Shape Optimization Using the RSM}

Cogging torque is produced because of the changing reluctance caused by the slots of a stator. This is a major drawback resulting in performance degradation. In order to reduce cogging torque, the factors which make cogging torque, should be minimized as much as possible in the process of motor design [2].

The RSM is well adapted to conduct the optimization for 

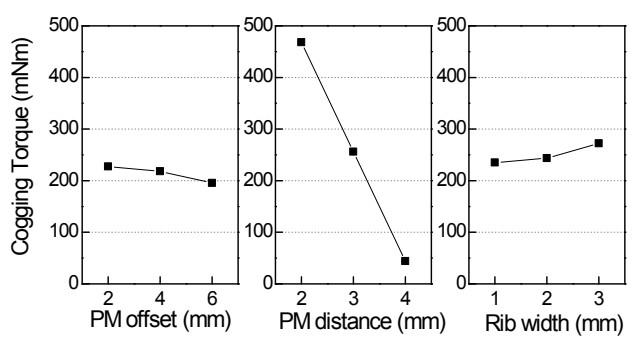

(a)
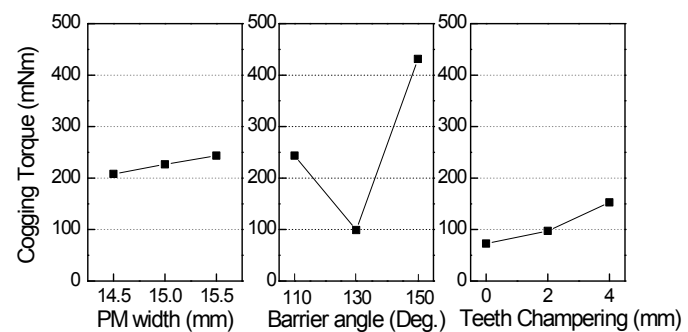

(b)

Fig. 4. Main effects of each parameter for cogging torque.

TABLE III

VARIABLES AND LEVEL OF MAIN EFFECTS

\begin{tabular}{c|c|c|c}
\hline $\begin{array}{c}\text { Design variables and } \\
\text { Level }\end{array}$ & $\mathrm{X}_{2}(\mathrm{~mm})$ & $\mathrm{X}_{5}(\mathrm{Deg})$. & $\mathrm{X}_{6}$ (Deg.) \\
\hline $1(-1)$ & 2 & 110 & 0 \\
\hline $2(0)$ & 3 & 130 & 2 \\
\hline $3(1)$ & 4 & 150 & 4 \\
\hline
\end{tabular}

complicated problems during design. The RSM procedures seek to find the relationship between the design variables and the response and to determine the optimum point through the statistical fitting method using the observed datum [3]-[5].

A quadratic approximation function of the response model is commonly used to construct the fitted response surface.

In general, the response model can be written as follows [6].

The true response $\eta$ can be written as:

$$
\eta=f\left(\xi_{1}, \xi_{2}, \ldots, \xi_{k}\right)
$$

where the variables $1,2, \ldots, \mathrm{k}$ are expressed in natural units of a measurement, called natural variables.

The experimentally obtained response y differs from the expected value $\eta$ due to random experimental errors. The relation between y and $\eta$ may be written as:

$$
y=f\left(x_{1}, x_{2}, \ldots, x_{k}\right)+\text { error }
$$

In many cases, the approximating function $\mathrm{f}$ of the true response $\eta$ is normally chosen to be either a first-order or a second-order polynomial model, which is based on Taylor series expansion.

In general, the first-order model is:

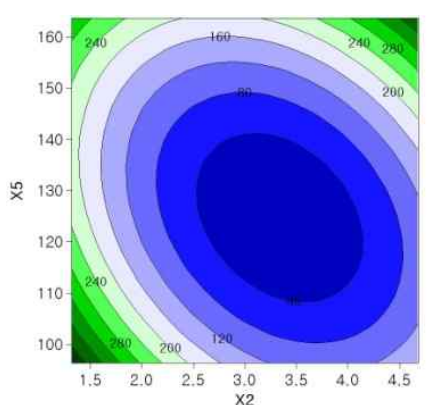

(a)

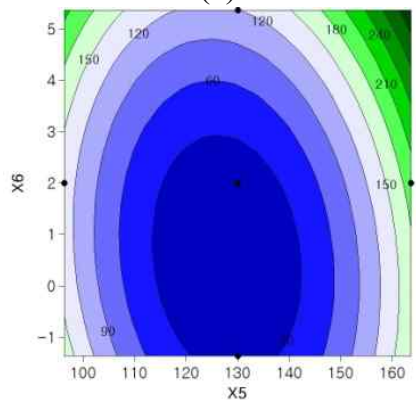

(b)

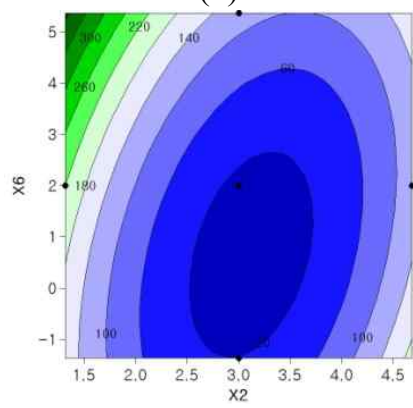

(c)

Fig. 5. Cogging torque with respect to (a) distance from airgap(X2) vs. angle between flux barrier and permanent(X5) (b) angle between flux barrier and permanent magnet(X5) vs. chamfering angle of stator teeth (X6) and (c) distance from $\operatorname{airgap}(\mathrm{X} 2)$ vs. chamfering angle of stator teeth(X6).

$$
f\left(x_{1}, x_{2}, \ldots, x_{k}\right)=\beta_{0}+\beta_{2} x_{2}+, \ldots+\beta_{k} x_{k}
$$

And the second-order model is:

$f\left(x_{1}, x_{2}, x_{3}\right)=b_{0}+\sum_{j=1}^{3} b_{j} x_{j}+\sum_{i \neq 1}^{3} b_{i j} x_{i} x_{j}+\sum_{i=j}^{3} b_{j j} x_{j}^{2}+\varepsilon$

where $\mathrm{bj}$, bij, and bjj are estimated by a regression from experiments and $\varepsilon$ is the error estimate.

Fig. 3 shows a flowchart of the optimum design steps. In the design of the experiments, the various factors that influence the properties of a product are selected, and then experiments are conducted to determine the relationship between the properties and the factors. A response is generally obtained from real experiments or computer simulations. In this paper, the FEM is used as a numerical experiment to obtain the response because it provides fairly accurate results and can be used for prediction 


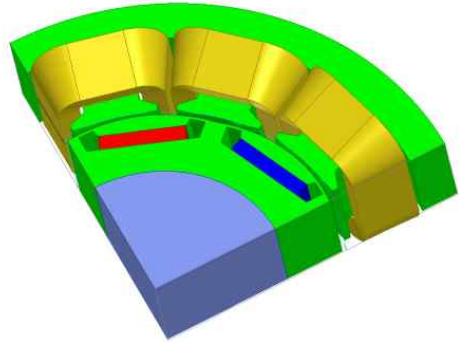

(a)

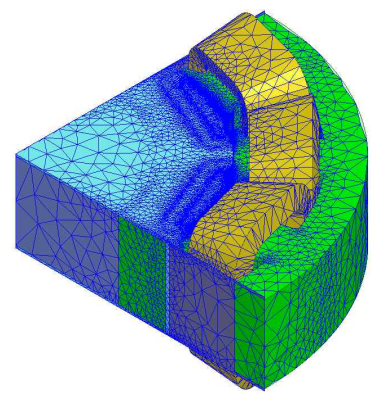

(b)

Fig. 6. IPMSM (a) 3-D structure and (b) mesh on analysis.

during the design.

The parameters given in Table II have been analyzed in terms of cogging torque. Fig. 4 shows the main effects of each parameter on cogging torque. X2, X5 and X6 were confirmed as the main factors affecting cogging torque. Accordingly, the design domain for the RSM is mainly decided by the plots of the main effects, as shown in Table III.

In order to determine the equations of the response surface, several experimental designs have been developed in an attempt to approximate the equation using the smallest number of experiments.

The central composite design has been used to get smallest number of experiments. As a result of the RSM process, the obtained optimal parameters are shown in Table IV and the initial values are compared with the optimum values [7].

\section{MAIN CHARACTERISTICS COMPARISON FOR TWO MODELS BY THE FEM}

The optimal designed model was analyzed and compared with initial model using 2 and 3 dimensional (2-D, 3-D) FEM. In the 2-D, 3-D FEM calculations, a commercial FEM package named "Ansys Maxwell” was used.

Fig. 6 (a) shows the detailed structure of the optimum model expressed to 3-D. For a more accurate simulation the models are composed of 3,064,625 tetrahedral elements, as shown in Fig 6 (b).

Fig. 7 shows the magnetic flux density distribution and the magnetic vector of the IPMSM.

Fig. 8 shows the airgap flux density plot for a period of the optimum model compared with the initial model. It more

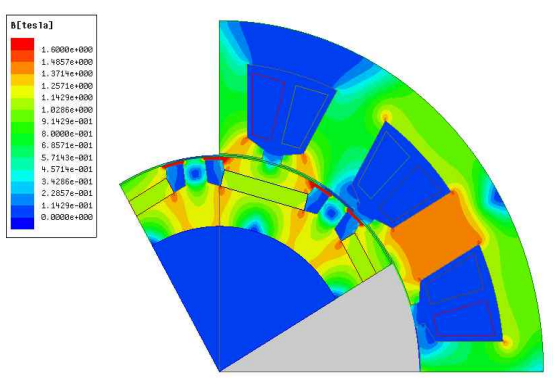

(a)

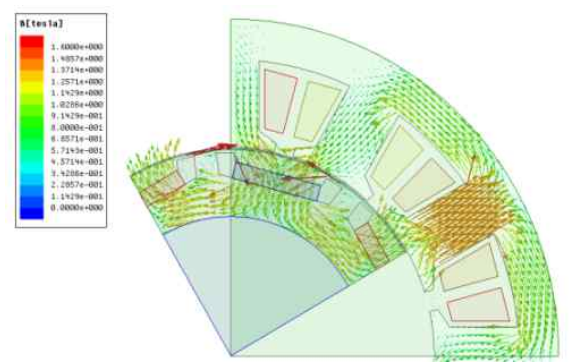

(b)

Fig. 7. Magnetic phenomenon (a) Magnetic flux density distribution and (b) magnetic flux vector.

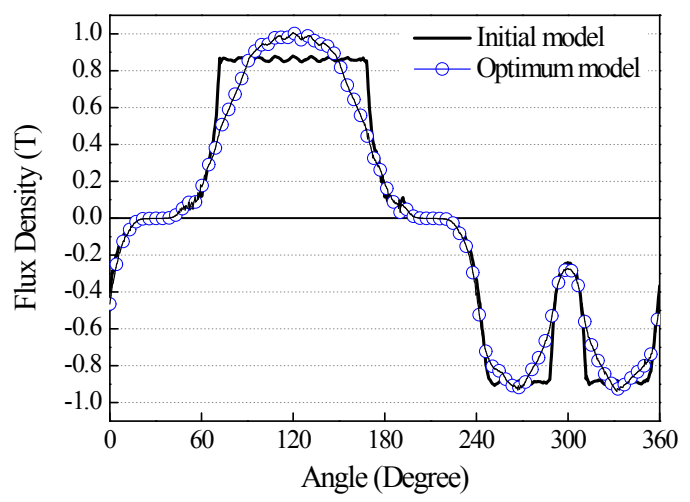

Fig. 8. Flux density plot at airgap.

closely resembles a sinusoidal form.

Fig. 9 shows the main characteristics, which are the cogging torque, back-EMF, and THD. The results show an overall comparison between the initial and the optimum model at a glance. The obtained results of the optimum model, which conducted an optimization through the RSM, show improved performance. In particular, the cogging torque focused on a diminution in this study is highly reduced without having a large influence on other performances.

Fig. 10 represents the harmonic spectrum of the no load EMF normalized by the fundamental amplitude of the two models for a detailed comparison. The 5red harmonic order of the optimum model is much lower than the initial model. The improved result of the THD indicates a remarkably decrease of about $11.2 \%$. On the other hand, the result which approached a sinusoidal waveform shows greater performance under sine wave drive conditions. 


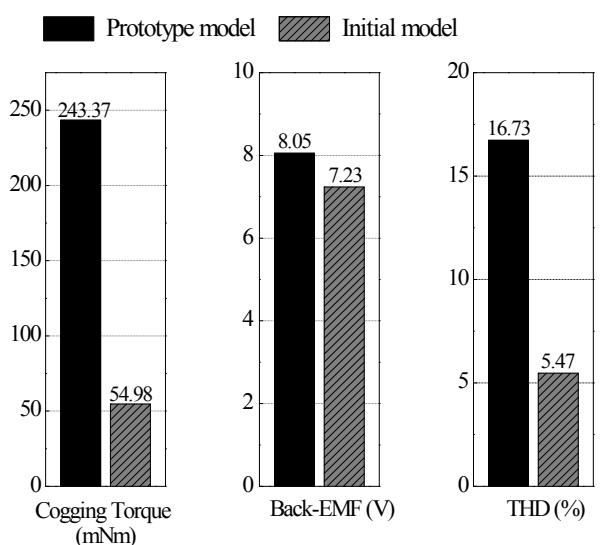

Fig. 9. Main Characteristics.

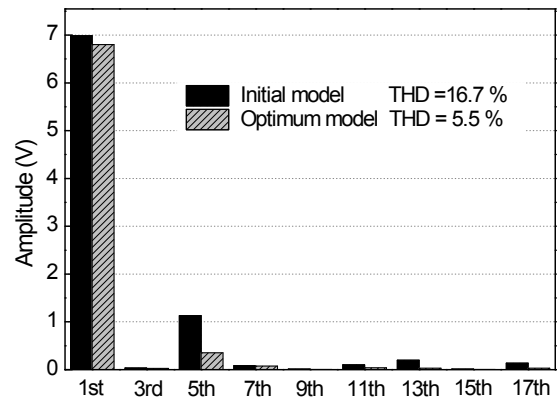

Fig. 10. Comparison of harmonic order.

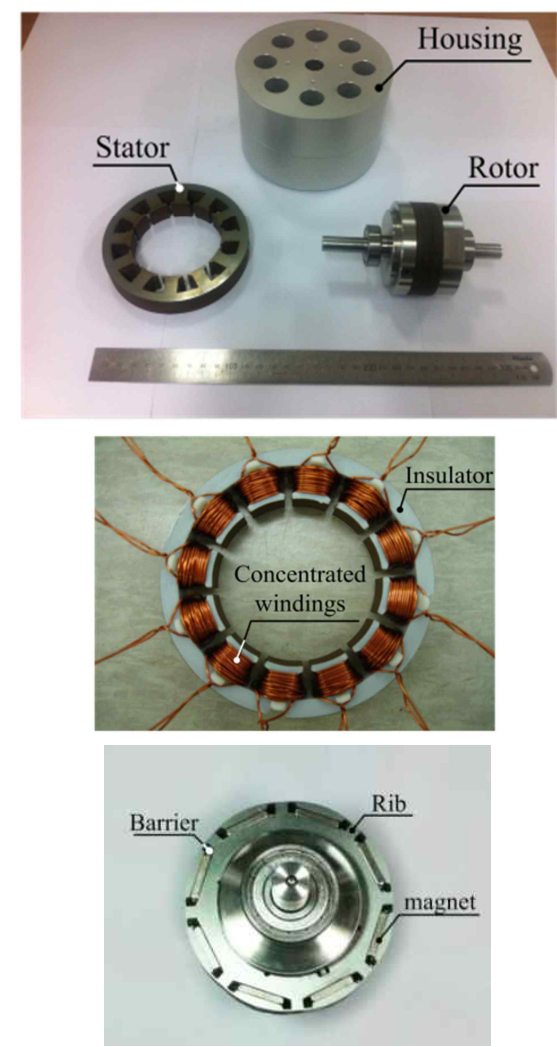

Fig. 11. Components of the IPMSM.

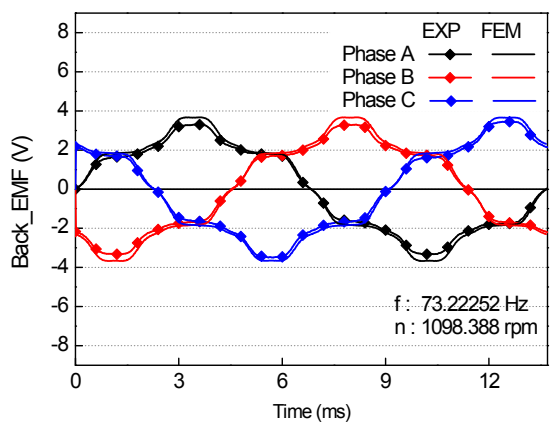

(a)

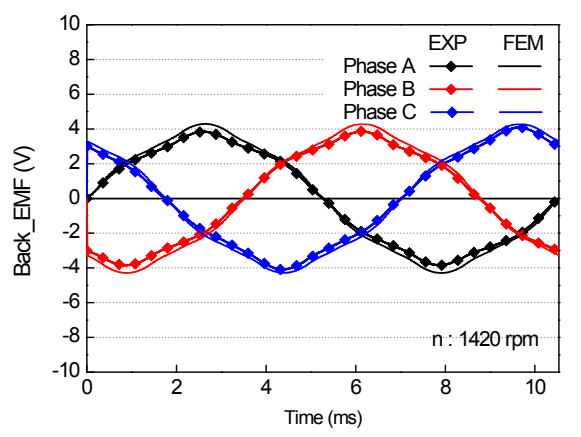

(b)

Fig. 12. Measued noload-back emf. (a) initial model (b) optimum model.

In order to verify the modeled characteristics, the initial and optimum IPMSMs have been manufactured. Fig. 11 shows the concentrated stator, rotor and housing for the IPMSMs. The stator and rotor were laminated with silicon steel sheets, to minimize the eddy currents. In addition, the stator was covered with insulator for insulation of the concentrated stator surface and twined coil at the operating state.

Fig. 12 shows the no load back-EMF of the initial and optimum models, respectively. It can be seen that there is no significant difference in the measured and calculated results when considered within the error range. It can also be seen that the back-EMF of the optimum model more closely resembles the sinusoidal form than the initial model.

\section{CONCLUSIONS}

This paper proposed a stator and rotor shape optimum design of an IPMSM using the RSM. On the basis of FEM simulation, the optimum model was predicted in terms of the cogging torque, back-EMF and THD. This model was then compared with the initial model. As a result, the cogging torque, which causes vibration and noise, can be greatly reduced by determining the optimal design point. Furthermore, the results show that there is only a slight decreased in other performances. The experimental results including the back-EMF are mostly in agreement when compared with the FEM results. 


\section{ACKNOWLEDGMENT}

This study was financially supported by the research fund of Chungnam National University, 2011.

\section{REFERENCES}

[1] T. Ishikawa, M. Yamada, and N. Kurita, "Design of magnet arrangement in interior permanent magnet synchronous motor by response surface methodology," IEEE Trans. Magn., Vol. 47, No. 5, pp. 1290-1293, May 2011.

[2] A. Wang, Y. Jia and W. L. Soong, "Comparison of five topologies for an interior permanent-magnet machine for a hybrid electric vehicle," IEEE Trans. Magn., Vol. 47, No. 10, pp. 3606-3609, Oct. 2011.

[3] R. H. Myers, Response Surface Methodology, New York : Wiley, 1995

[4] P. Skov-Hansen, Z. Han, and J. I. Bech, "Stresses and strains in multy-filament HTS tapes," IEEE Trans Appl Supercon, Vol. 9, No. 2, pp. 2617-2620, Jun. 1999.

[5] R. Rong, D. A. Lowther, Z. Malik, H. Su, J. Nelder, and R. Spence, "Applying response surface methodology in the design and optimization of electromagnetic devices," IEEE Trans. Magn, Vol. 33, No. 2, pp. 1916-1919, Mar. 1999.

[6] Y. K. Kim, Y. S. Jo, J. P. Hong, and J. Lee, "Approach to the shape optimization of racetrack type high temperature superconducting magnet using response surface methodology," Cryogenics, Vol 41, No. 1, pp. 39-47, Jan. 2001.

[7] J. S. Yu and H. W. Cho, "Optimum design of interior permanent magnet motor for automotive cooling device," Applied Machines and Materials, Vols. 260-261, pp. 581-586, Dec. 2012.

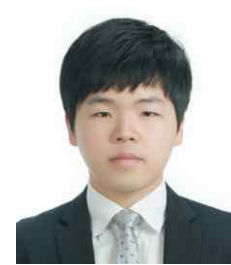

Ju-Seong Yu received his B.S. in Electric, Electronic, and Communication Engineering Education from Chungnam National University, Daejeon, Korea, in 2011. He is currently pursuing his M.S. in Electrical Engineering at Chungnam National University. His current research interests motors/generators.

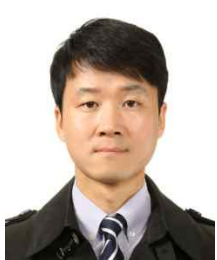

Han-Wook Cho received his B.S., M.S. and $\mathrm{Ph} . \mathrm{D}$. in Electrical Engineering from Chungn am National University, Daejeon, Korea, in 2 002, 2004 and 2007, respectively. From 2007 to 2010, he was with the KIMM (Korea Instit ute of Machinery and Materials), Daejeon, Ko rea. Since 2010, he has been with Chungnam National University, where he is currently an Assistant Professor in the Department of Electric, Electronic, and Communication Engineering Education. His current research in terests include design and analysis of motors/generators, electro mechanical systems, and performance assessment of renewable e nergy systems.

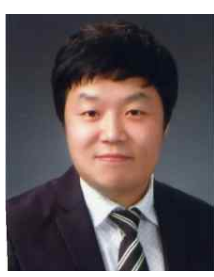

Jang-Young Choi received his B.S., M.S. and $\mathrm{Ph} . \mathrm{D}$. in Electrical Engineering from Chungnam National University, Daejeon, Korea, in 2003, 2005 and 2009, respectively. $\mathrm{He}$ is currently an Assistant Professor in the Department of Electrical Engineering, Chungnam National University. His current research interests include design and analysis of motors/generators, and new electrical energy systems.

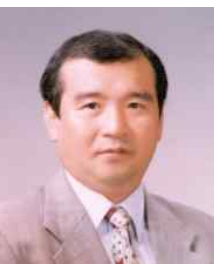

Seok-Myeong Jang received his Ph.D. in Electrical Engineering from Hanyang University, Seoul, Korea, in 1986. He is currently a Professor in the Department of Electrical Engineering, Chungnam National University, Daejeon, Korea. In 1989, he worked as a Visiting Researcher in the Department of Electrical Engineering, University of Kentucky, Lexington, KY.

His current research interests include design and analysis of wind generators, electromechanical systems, and performance assessment of renewable energy systems.

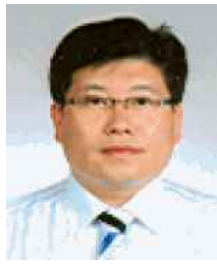

Sung-Ho Lee received his B.S., M.S. and $\mathrm{Ph}$ .D. in Electrical Engineering from Chungna m National University, Daejeon, Korea, in 19 97, 1999 and 2003, respectively. From 2003 t o 2007, he was with the LG D/A Research Ce nter, Korea. Since 2007, he has been a Princi pal Researcher at KITECH (Korea Institute o f Industrial Technologies), Gwangju, Korea.

His current research interests include design and analysis of mot ors/generators, electromechanical systems and renewable energy systems. 